\title{
Are atrophic long-bone nonunions associated with low-grade infections?
}

\author{
This article was published in the following Dove Press journal: \\ Therapeutics and Clinical Risk Management \\ 15 December 2015 \\ Number of times this article has been viewed
}

\section{Ulrike Dapunt ${ }^{1}$ \\ Ole Spranger ${ }^{2}$ \\ Simone Gantz' \\ Irene Burckhardt ${ }^{3}$ \\ Stefan Zimmermann ${ }^{3}$ \\ Gerhard Schmidmaier ${ }^{2}$ \\ Arash Moghaddam² \\ 'Center for Orthopedics, Trauma Surgery and Spinal Cord Injury, ${ }^{2}$ HTRG-Heidelberg Trauma Research Group, Trauma and Reconstructive Surgery, Center for Orthopedics, Trauma Surgery and Spinal Cord Injury, Heidelberg University Hospital, ${ }^{3}$ Department for Infectious Diseases, Medical Microbiology and Hygiene, Heidelberg, Germany}

Correspondence: Ulrike Dapunt Center for Orthopedics, Trauma Surgery and Spinal Cord Injury, Heidelberg University Hospital, 200A Schlierbacher Landstrasse, Heidelberg 69118, Germany $\mathrm{Tel}+4962215635561$

Fax +49 622I 5626300

Email ulrike.dapunt@med.

uni-heidelberg.de

\begin{abstract}
Impaired fracture healing, especially when associated with bacterial infection, is a severe complication following long-bone fractures and requires special treatment. Because standard diagnostic techniques might provide falsely negative results, we evaluated the sonication method for detection of bacteria on implants of patients with fracture nonunions. A total of 49 patients with a nonunion (group NU) and, for comparison, 45 patients who had undergone routine removal of osteosynthetic material (group OM), were included in the study. Five different diagnostic methods (culture of tissue samples, culture of intraoperative swabs, histopathology of tissue samples, culture of sonication fluid, and $16 \mathrm{~S}$ ribosomal DNA polymerase chain reaction of sonication fluid) were compared and related to clinical data. Among the diagnostic tests, culture of sonication fluid demonstrated by far the highest detection rate of bacteria (57\%) in group $\mathrm{NU}$, and rather unexpectedly $40 \%$ in group OM. Culture of sonication samples also revealed a broad spectrum of bacteria, in particular Propionibacterium spp. In conclusion, our results indicate that more bacteria can be detected on implants of patients with atrophic nonunions of long-bone fractures by means of the sonication procedure, which provides a valuable additional diagnostic tool to decide on a surgical procedure (eg, two-step procedure) and to further specify antimicrobial therapy.
\end{abstract}

Keywords: sonication, osteosynthetic material, osteomyelitis

\section{Background}

Fracture nonunions caused by bacterial infections still pose one of the most feared complications in the field of orthopedic surgery. ${ }^{1}$ Therapy frequently consists of repeated and extensive debridement accompanied by prolonged antibiotic treatment, which puts patients at high risk of associated complications, reduces quality of life due to functional disabilities, and results in high socioeconomic costs. ${ }^{2-7}$

In particular, patients with open fractures are at risk of infection, but also patients with closed fractures and severe soft-tissue damage develop infections following osteosynthetic procedures. ${ }^{8,9}$ Staphylococcus aureus has been described as the main causative agent in approximately $50 \%-60 \%$ of cases, ${ }^{10-12}$ but recently other species also, such as Propionibacterium spp., have been linked to implant-associated infections. ${ }^{13,14}$

Infections of the bone are particularly difficult to treat, since bacteria form so-called biofilms on the implant surface, which make them more resistant to antibiotics and biocides. ${ }^{15-18}$ The diagnosis of biofilm infections by standard microbiological diagnostics (cultures of tissue samples or swabs) often yields falsely negative results, and it has been argued that up to $40 \%$ of cases are falsely deemed aseptic. ${ }^{19-21}$

Sonication of removed implants has led to an improved detection rate, because the majority of bacteria are attached to the implant surface, and thus can be gently removed. ${ }^{22,23}$ Aim of this study was to apply sonication to implants from patients with 
atrophic nonunions and compare the results with standard diagnostic techniques (culture of tissue samples, intraoperative swabs, histopathology of tissue samples). We hypothesized that more nonunions are associated with an infection and that sonication might demonstrate a broader spectrum of bacteria that so far has gone undetected. We also compared the results with implants from patients who had undergone routine removal of osteosynthetic material.

\section{Materials and methods}

\section{Patient-derived material}

From March 2014 to September 2014, 94 patients were included in this study at the Clinic for Orthopedics and Trauma Surgery, Heidelberg University Hospital. A total of 49 patients were scheduled for surgery due to long-bone nonunion, and underwent implant removal or exchange (an example of a patient treated for fracture nonunion is shown in Figure 1). Diagnosis of nonunion was made due to patients' complaints, clinical examination, and by conventional X-ray and/or computed tomography scan. The diagnosis of an infectious nonunion was based on clinical evaluation (reddening, swelling, hyperthermia, pain, pus intraoperatively, existence of a sinus tract) and laboratory results (elevated C-reactive protein [CRP] concentration and white cell count).

The criteria for an infection were a sinus tract, pus intraoperatively, or at least three positive signs just mentioned. During surgery, an intraoperative swab of the wound, as well as one to three tissue samples, were taken directly adjacent to the
A

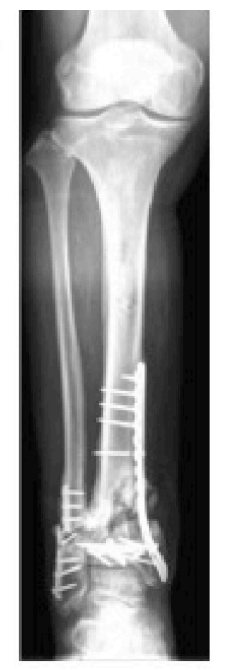

C

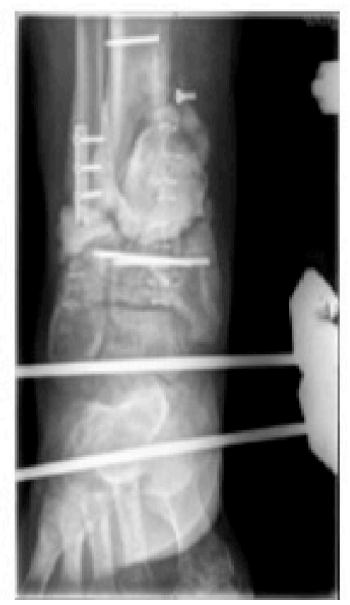

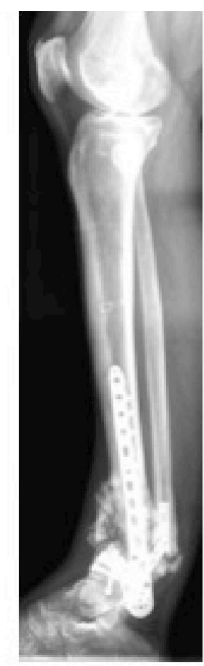

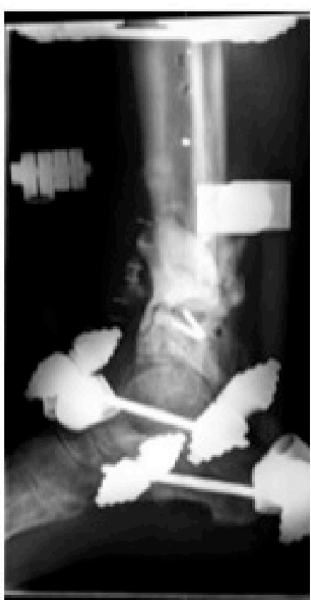

B

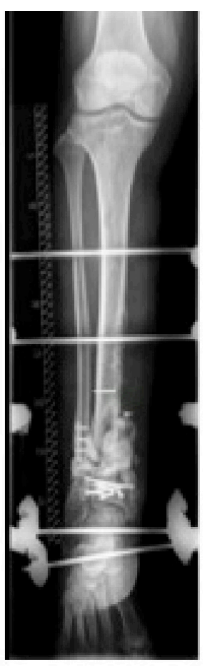

D

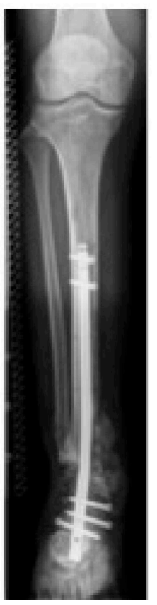

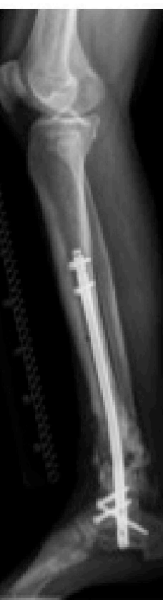

Figure I Treatment of an infectious nonunion by means of the Masquelet technique.

Notes: Due to a Staphylococcus warneri infection (as detected by culture of sonication fluid), the patient showed impaired fracture healing of the distal tibia and fibula 20 months after fracture (A). According to Masquelet step I, osteosynthetic material was removed and extensive debridement performed, followed by implantation of a PMMA-spacer and application of an external fixer (B, C). Due to impaired wound healing and persistent exudation, the PMMA spacer was exchanged and debridement performed 2 months later. After 4 months, the wound had healed and Masquelet step 2 was performed. The PMMA spacer was removed, followed by reosteosynthesis using an Expert Tibial Nail Protect; BMP-7 and cancellous bone of the femur (using the reamer-irrigator-aspirator system) were implanted into the fracture gap. The patient showed improved fracture healing 26 months after fracture (D).

Abbreviation: PMMA, polymethyl methacrylate. 
implant, and if possible each sample was divided and sent to the Microbiology Department and the Pathology Department for examination. In cases of very small tissue specimens, the entire sample was sent to the Microbiology Department.

Additionally, 45 patients who had undergone routine removal of osteosynthetic material were included in this study. There were no clinical or laboratory signs of an infection, and X-rays showed satisfactory fracture healing. Swabs and tissue samples were collected as described earlier, though due to small surgical incisions, only a limited number of tissue samples were available for histopathological analysis.

To test the sonication procedure for possible contamination, ten randomly chosen sterile screws were collected during different surgical procedures and treated according to the sonication protocol. All of these samples tested negative for bacterial contamination. All of the sonication samples were handled by one person only. The study was approved by the ethics committee of the Faculty of Medicine of Heidelberg University, and written informed consent was obtained from the patients.

\section{Patient data}

A total of 49 patients with nonunions (group NU) and 45 patients undergoing routine removal of osteosynthetic material (group OM) were included in the study. The patients' average age was 49.3 (22-81) years for group NU and 45.2 (18-80) years for group OM. There were 15 female and 34 male patients in group NU, and 22 females and 23 males in group OM. None of the patients was under immunosuppressive therapy; $20.4 \%$ of group NU and $2.2 \%$ of group OM were diagnosed with diabetes (clinical data are summarized in Table 1).

\section{Sonication of implants}

The removed osteosynthetic materials (nails, screws, plates) were placed into sterile plastic boxes in various sizes depending on implant size (Bandelin Electronic GmbH \& Co KG, Berlin, Germany) in the operating room. Enough Ringer's solution to cover the implant was added (50-200 mL). They were then placed in an ultrasound bath (Ultrasonic TI-H 20; Elma Schmidbauer GmbH, Singen, Germany) and treated with ultrasonic power of $100 \%(250 \mathrm{~W})$ and ultrasonic frequency of $45 \mathrm{kHz}$ for 1 minute. These settings have been shown to detach bacteria from the implant surface while ensuring bacterial viability. ${ }^{24}$ Following sonication, $10 \mathrm{~mL}$ of the fluid was placed into each aerobic and anaerobic bloodculture bottle (Bactec plus aerobic/anaerobic; BD, Franklin Lakes, NJ, USA) (Figure 2). The bottles were incubated at $36^{\circ} \mathrm{C}$ until positive or for a maximum of 14 days in a Bactec
FX (BD). Positive bottles were subcultured on Columbia 5\% sheep-blood agar (BD), chocolate agar, MacConkey agar, and Streptococcus-selective (SCS) agar (all BioMérieux SA, Marcy-l'Etoile, France) until positive. All positive samples showed growth on the subculture the next day. Bacteria were identified by a matrix-assisted laser desorption/ionization time-of-flight (MALDI-TOF) mass spectrometer (Microflex; Bruker Corporation, Billerica, MA, USA). Susceptibility testing was done using the Vitek $^{\circledR} 2$ microbial identification system (BioMérieux). Additionally, eubacterial 16S ribosomal DNA (rDNA) polymerase chain reaction (PCR) was performed as previously described. ${ }^{25}$

\section{Diagnostic procedures}

Tissue samples were processed according to the following protocol. After arrival at the lab, the tissue was ground using a porcelain mortar, followed by the addition of $1 \mathrm{~mL}$ of $0.9 \%$ $\mathrm{NaCl}$. This suspension was inoculated onto Columbia 5\% sheep blood agar (BD), chocolate agar, MacConkey agar, SCS agar, Schaedler Neo Vanco $+5 \%$ sheep blood (SNVS) agar (all BioMérieux), and thioglycolate broth (BD), and then Gram staining was performed. Plates and broth were incubated until positive or for a maximum of 5 days at $36^{\circ} \mathrm{C}$ in $5 \% \mathrm{CO}_{2}$ or under anaerobic conditions. Identification of bacteria was done with the MALDI-TOF mass spectrometer. Susceptibility testing was done using the Vitek 2 microbial identification system.

For intraoperative swabs, the eSwab system was used. After arrival at the lab, $10 \mu \mathrm{L}$ of liquid Amies was inoculated onto Columbia 5\% sheep-blood agar (BD), chocolate agar, MacConkey agar, SCS agar, SNVS agar (all BioMérieux), and thioglycolate broth (BD), and then Gram staining was performed. Plates and broth were incubated for 2 days at $36^{\circ} \mathrm{C}$ in $5 \% \mathrm{CO}_{2}$ or under anaerobic conditions. Identification and susceptibility testing was done as described earlier.

The incubation time was chosen according to microbiological expertise (swabs for 2 days and tissue samples for 5 days). Swabs were transported in liquid Amies transport media with flocked swabs. These swabs released their content completely into the transport medium, which was used for the inoculation of plates. On the other hand, the tissue had to be ground before inoculation, and part of it was put into an enrichment broth. Therefore, with tissue samples, sometimes there were cases that were not culture-positive until day 5 .

For histopathological diagnostics, the samples were fixed in formalin and embedded in paraffin, and after the cutting slices of $2 \mu \mathrm{m}$ thickness, routine hematoxylin-eosin staining was performed. The criterion for an implant-associated 
Table I Clinical data

\begin{tabular}{|c|c|c|c|c|c|}
\hline \multirow[t]{2}{*}{ Characteristics } & \multicolumn{2}{|l|}{ Group NU } & \multicolumn{2}{|l|}{ Group OM } & \multirow[t]{2}{*}{$P$-value } \\
\hline & $\mathbf{n}$ & $\%$ & $\bar{n}$ & $\%$ & \\
\hline Sex & & & & & $P=0.092$ \\
\hline Male & 34 & 69.4 & 23 & 51.1 & \\
\hline Female & 15 & 30.6 & 22 & 48.9 & \\
\hline Age (years) & & & & & $P=0.778$ \\
\hline Mean ( \pm standard deviation) & $49.3( \pm 14.80)$ & & $45.2( \pm 16.68)$ & & \\
\hline Median (range) & $53(22-8 I)$ & & $46(18-80)$ & & \\
\hline Smoking status & & & & & $P=0.166$ \\
\hline Smokers & 17 & 34.7 & 9 & 20.0 & \\
\hline Former smoker/nonsmokers & 32 & 65.3 & 36 & 80.0 & \\
\hline Diabetes mellitus & & & & & $P=0.008$ \\
\hline Yes & 10 & 20.4 & I & 2.2 & \\
\hline No & 39 & 79.6 & 44 & 97.8 & \\
\hline Implants & & & & & $P=0.126$ \\
\hline Humerus/olecranon & 3 & 6.1 & 5 & II.I & \\
\hline Ulna/radius & 3 & 6.1 & 10 & 22.2 & \\
\hline Clavicle & I & 2.0 & 4 & 8.9 & \\
\hline Pelvis & I & 2.0 & 0 & 0 & \\
\hline Femur & 16 & 32.7 & 7 & 15.6 & \\
\hline Fibula/tibia & 20 & 40.8 & 16 & 35.6 & \\
\hline Foot & 5 & 10.2 & 3 & 6.7 & \\
\hline Open/closed fracture & & & & & $P<0.001$ \\
\hline Closed & 23 & 46.9 & 41 & 91.1 & \\
\hline Open $1^{\circ}$ & 0 & 0 & 0 & 0 & \\
\hline Open $2^{\circ}$ & 12 & 24.5 & 0 & 0 & \\
\hline Open $3^{\circ}$ & 6 & 12.2 & 0 & 0 & \\
\hline Postosteotomy & 5 & 10.2 & I & 2.2 & \\
\hline Not specified & 3 & 6.1 & 3 & 6.7 & \\
\hline $\begin{array}{l}\text { Number of previous surgeries at } \\
\text { the same location }\end{array}$ & & & & & $P<0.001$ \\
\hline 1 & 16 & 32.7 & 44 & 97.8 & \\
\hline 2 & 12 & 24.5 & 1 & 2.2 & \\
\hline 3 & 8 & 16.3 & 0 & 0 & \\
\hline 4 & 6 & 12.2 & 0 & 0 & \\
\hline 5 & 0 & 0 & 0 & 0 & \\
\hline 6 & 2 & 4.1 & 0 & 0 & \\
\hline 7 & 2 & 4.1 & 0 & 0 & \\
\hline 8 & 0 & 0 & 0 & 0 & \\
\hline 9 & 0 & 0 & 0 & 0 & \\
\hline$>9$ & 3 & 6.1 & 0 & 0 & \\
\hline Mean ( \pm standard deviation) & $3.4( \pm 4.69)$ & & $1.0( \pm 0.15)$ & & \\
\hline Median (range) & $2(|-3|)$ & & $I(I-2)$ & & \\
\hline Time since fracture (years) & & & & & $P=0.026$ \\
\hline$<1$ & 15 & 30.6 & 15 & 33.3 & \\
\hline $1-2$ & 16 & 32.7 & 24 & 53.3 & \\
\hline $2-5$ & 9 & 18.4 & 6 & 13.3 & \\
\hline $5-10$ & 4 & 8.2 & 0 & 0 & \\
\hline $10-20$ & 5 & 10.2 & 0 & 0 & \\
\hline Mean ( \pm standard deviation) & $3.4( \pm 4.39)$ & & $1.5( \pm 0.98)$ & & \\
\hline Median (range) & $1.5(0.5-15)$ & & $1.5(0.5-3.5)$ & & \\
\hline
\end{tabular}

Abbreviations: NU, nonunion; OM, osteosynthetic material.

infection was at least 23 polymorphonuclear neutrophils per ten high-power fields. ${ }^{26}$

\section{Statistical tests}

The concordance of the results of the five diagnostic methods and of the clinical evaluation was calculated using Cohen's $\kappa$-test, and the interpretation of the test was as in Landis and Koch. ${ }^{27}$ The correlation between CRP concentration/white blood cell count and culture of either sonication fluid or tissue samples was calculated by the Spearman test. With regard to the clinical data (Table 1), differences between groups were calculated using the unpaired $t$-test (age), Mann-Whitney 
A
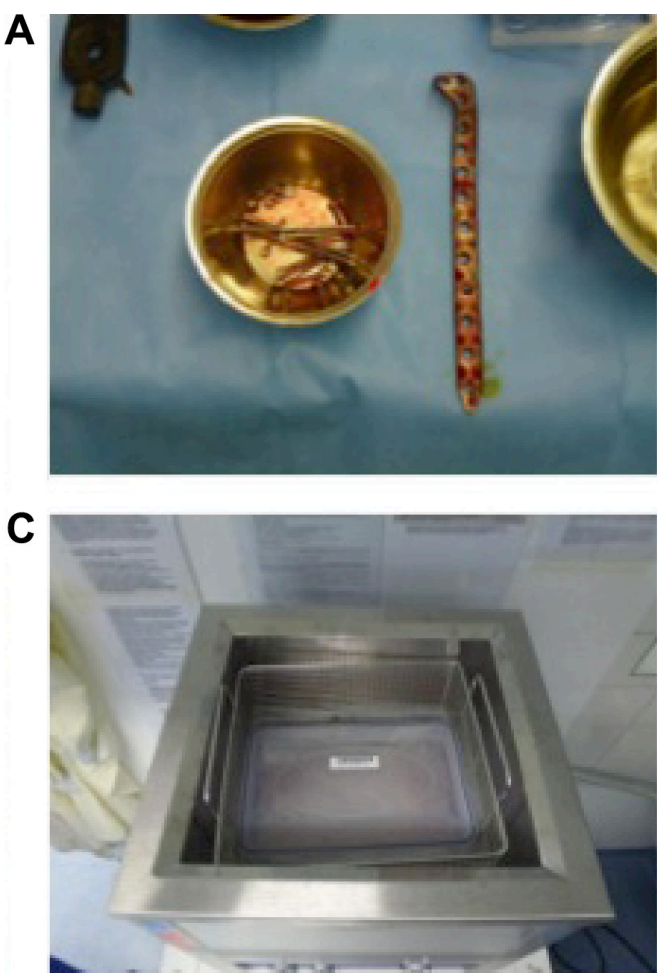

B

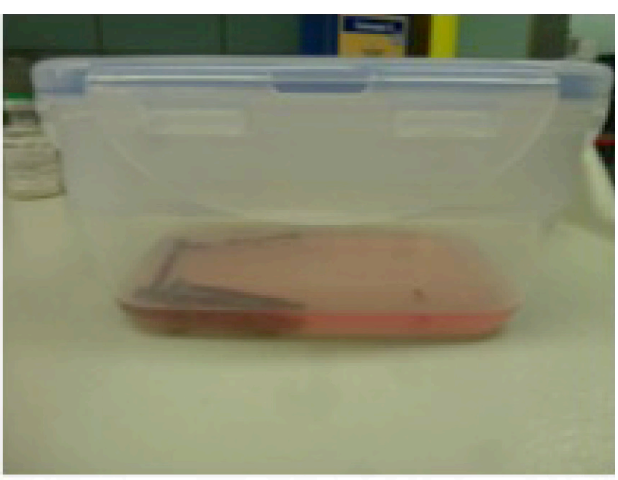

D

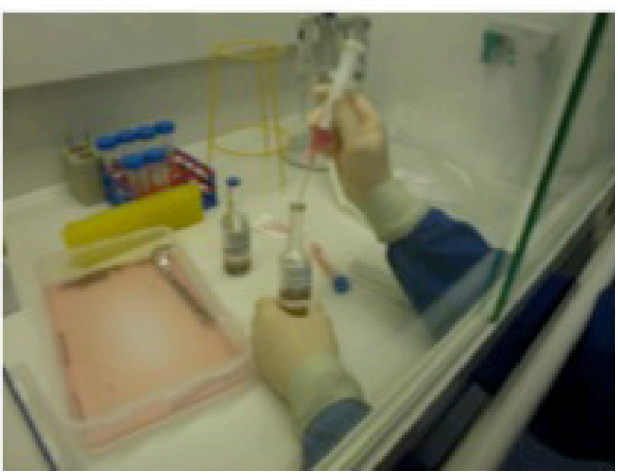

Figure 2 Sonication procedure.

Notes: Removed osteosynthetic material was placed in sterile plastic boxes, and Ringer's solution was added (A, B). The box was placed in the ultrasound bath (C). After sonication, $10 \mathrm{~mL}$ of the fluid was placed into each blood-culture bottle (D).

$U$-test (number of previous surgeries at the same location), or Fisher's exact test (all others).

\section{Results}

\section{Evaluation of diagnostic methods in implant infections}

Implants were removed from various locations (Table 1). Conventional microbial diagnostic of tissue samples and swabs was performed, as was histopathological examination of tissue samples. After sonication of the removed implant, the presence of bacteria in the fluid was assessed by conventional culture and eubacterial $16 \mathrm{~S}$ rDNA PCR. As summarized in Table 2, more bacteria were detected following culture of sonication fluid (57.1\% group NU, $40 \%$ group OM) compared to culture of tissue samples $(10.2 \%$ group NU, $17.2 \%$ group OM), histology of tissue samples
(9.3\% group NU, 25\% group OM), and PCR analysis of sonication fluid (11.9\% group NU, $10.5 \%$ group OM). Culture of intraoperative swabs provided the least positive results $(6.8 \%$ group NU, $0 \%$ group OM) (data summarized in Table 2).

Agreement or nonagreement of these five diagnostic methods was determined using Cohen's $\kappa$-test. There was only one moderate agreement between culture of tissue samples and culture of intraoperative swabs; all other diagnostic tests revealed fair, slight, or no agreement (data summarized in Table 3).

\section{Clinical evaluation}

Patients with nonunions were evaluated according to the aforementioned clinical criteria for an infection (see Materials and methods section). In this group, 16 of 49 patients $(32.7 \%)$ showed signs suspicious of an infection.

Table 2 Number of patient samples acquired from group NU and group OM, and number of positive results

\begin{tabular}{|c|c|c|c|c|c|}
\hline Group NU (n=49) & $\begin{array}{l}\text { Number } \\
\text { of patients }\end{array}$ & Positive & Group OM (n=45) & $\begin{array}{l}\text { Number } \\
\text { of patients }\end{array}$ & Positive \\
\hline Culture of tissue samples & 49 & $5 / 49(10.2 \%)$ & Culture of tissue samples & 29 & $5 / 29(17.2 \%)$ \\
\hline Culture of intraoperative swab & 44 & $3 / 44(6.8 \%)$ & Culture of intraoperative swab & 29 & $0 / 29$ \\
\hline Culture of sonication fluid & 49 & $28 / 49(57.1 \%)$ & Culture of sonication fluid & 45 & $18 / 45(40.0 \%)$ \\
\hline I6S rDNA PCR of sonication fluid & 42 & $5 / 42(11.9 \%)$ & I6S rDNA PCR of sonication fluid & 38 & $4 / 38(10.5 \%)$ \\
\hline Histopathology of tissue samples & 32 & $3 / 32(9.3 \%)$ & Histopathology of tissue samples & 8 & $2 / 8(25 \%)$ \\
\hline
\end{tabular}

Abbreviations: NU, nonunion; OM, osteosynthetic material; rDNA, ribosomal DNA; PCR, polymerase chain reaction. 
Table 3 Agreement of diagnostic methods

\begin{tabular}{|c|c|c|}
\hline Agreement of & Group NU & Group OM \\
\hline Culture of tissue samples and culture of sonication fluid & $\kappa=0.090$, slight $(P=0.28 \mathrm{I})$ & $K=0.394$, fair $(P=0.019)$ \\
\hline Culture of intraoperative swab and culture of sonication fluid & $\kappa=0.065$, slight $(P=0.1 \mid 0)$ & $\kappa=0$, slight $(P=1.000)$ \\
\hline I6S rDNA PCR of sonication fluid and culture of sonication fluid & $\kappa<0$, no agreement $(P=0.715)$ & $\kappa=0.038$, slight $(P=0.735)$ \\
\hline Histopathology of tissue samples and culture of sonication fluid & $\kappa<0$, no agreement $(P=0.40 \mathrm{I})$ & $\kappa<0$, no agreement $(P=0.346)$ \\
\hline Culture of tissue samples and culture of intraoperative swab & $\kappa=0.535$, moderate $(P<0.00 I)$ & $\kappa=0$, slight $(P=1.000)$ \\
\hline Culture of tissue samples and I6S rDNA PCR of sonication fluid & $K=0.319$, fair $(P=0.039)$ & $\kappa=0.025$, slight $(P=0.905)$ \\
\hline Culture of tissue samples and histopathology of tissue samples & $K=0.262$, fair $(P=0.145)$ & $\kappa=0$, slight $(P=I)$ \\
\hline Culture of intraoperative swab and I6S rDNA-PCR of sonication fluid & $\kappa=0.168$, slight $(P=0.281)$ & $\kappa=0.000$, slight $(P=I)$ \\
\hline Culture of intraoperative swab and histopathology of tissue samples & $\kappa=0.350$, fair $(P=0.046)$ & $K=0$, slight $(P=I)$ \\
\hline I6S rDNA PCR of sonication fluid and histopathology of tissue samples & $\kappa<0$, no agreement $(P=0.516)$ & $\kappa=0$, slight $(P=I)$ \\
\hline
\end{tabular}

Notes: $\kappa<0$, no agreement, $\kappa=0-0.20$, slight; $\kappa=0.2 \mathrm{I}-0.40$, fair; $\kappa=0.4 \mathrm{I}-0.60$, moderate; $\kappa=0.6 \mathrm{I}-0.80$, substantial; $\kappa=0.8 \mathrm{I}-\mathrm{I}$, almost perfect.

Abbreviations: NU, nonunion; OM, osteosynthetic material; rDNA, ribosomal DNA; PCR, polymerase chain reaction.

Using the Cohen $\kappa$-score, we compared the clinical evaluation of an infection with culture of sonication fluid and with culture of tissue samples. There was no agreement between clinical evaluation and culture of sonication fluid $(\kappa<0)$ or 16S rDNA PCR of sonication fluid $(\kappa<0)$; there was slight agreement between clinical evaluation and culture of tissue samples ( $K=0.038)$, as well as culture of intraoperative swab $(\kappa=0.006)$, and fair agreement between clinical evaluation and histopathology of tissue samples $(\kappa=0.294)$.

Standard laboratory tests (CRP concentration and white cell count) were correlated with positive results of culture of sonication fluid and of culture of tissue samples by means of the Spearman test. We found no statistically significant correlation between these parameters.

\section{Identification of bacterial species}

We compared the bacterial species that were detected following culture of sonication fluid or culture of tissue samples (Tables 4 and 5). Culture of sonication fluid revealed a broader spectrum of bacteria, and in particular
Propionibacterium spp. were detected more reliably than by culture of tissue samples. When tissue samples were positive, only one bacterial species was detected by culture of tissue samples. Bacteria detected by culture of tissue sample and culture of sonication fluid in the same case were not always concurrent (Tables 4 and 5).

We also tried mapping bacteria found in certain locations, but due to the limited number of patients included in this study and the considerable variety of bacteria, no significant differences in distribution of bacteria could be determined (Table S1).

\section{Discussion}

Our results showed that $57.1 \%$ of atrophic nonunions of long-bone fractures were associated with bacteria on the implant surface if culture of implant sonication is performed. The strengths of the study were prospective study design, thoroughly documented clinical data, existence of a comparison group, and random testing of the sonication method. Limitations of the study were the number of patients

Table 4 Bacterial species detected following culture of tissue samples and culture of sonication fluid of patients with nonunions (group NU)

\begin{tabular}{lll}
\hline Species & Number of isolates \\
\cline { 2 - 3 } & Culture of tissue samples & Culture of sonication fluid \\
\hline Coagulase-negative Staphylococcus spp. & $2 / 5(40.0 \%)$ & $17 / 3$ I $(54.8 \%)$ \\
Citrobacter freundii & $1 / 5(20.0 \%)$ & - \\
Micrococcus lentus & $1 / 5(20.0 \%)$ & - \\
Enterobacter cloacae & $1 / 5(20.0 \%)$ & $1 / 3 \mid(3.2 \%)$ \\
Propionibacterium spp. & - & $2 / 3 \mid(6.4 \%)$ \\
Bacillus spp. & - & $5 / 3 \mid(16.1 \%)$ \\
Lactobacillus spp. & - & $1 / 3 \mid(3.2 \%)$ \\
Oceanobacterium caeni & - & $1 / 3 \mid(3.2 \%)$ \\
Micrococcus luteus & - & $2 / 3 \mid(6.4 \%)$ \\
Corynebacterium aurimucosum & - & $1 / 3 \mid(3.2 \%)$ \\
Brevibacterium frigoritolerans & - & $1 / 3 \mid(3.2 \%)$
\end{tabular}


Table 5 Bacterial species detected following culture of tissue samples and culture of sonication fluid of patients undergoing routine removal of osteosynthetic material (group OM)

\begin{tabular}{lll}
\hline Species & Number of isolates & Culture of sonication fluid \\
\cline { 2 - 3 } & Culture of tissue samples & $6 / 20(30.0 \%)$ \\
\hline Coagulase-negative Staphylococcus spp. & $2 / 5(40.0 \%)$ & $8 / 20(40.0 \%)$ \\
Propionibacterium acnes & $2 / 5(40.0 \%)$ & $1 / 20(5.0 \%)$ \\
Enterococcus faecalis & $1 / 5(20.0 \%)$ & $3 / 20(15.0 \%)$ \\
Bacillus spp. & - & $1 / 20(5.0 \%)$ \\
Sporolactobacillus laevolacticus & - & $1 / 20(5.0 \%)$ \\
Delftia acidovorans & - &
\end{tabular}

included not being sufficient for mapping of bacterial species (Table S1), varying number of tissue samples retrieved, lack of a generally accepted definition for implant-associated infections, and negative PCR results, possibly due to a dilution effect.

Fracture repair is a complex multistep process, which when disturbed may result in nonunion of the bone..$^{28}$ Bacterial infections are one possible reason for impaired fracture healing and diagnostics, and treatment of infectious nonunions still pose a challenge in the field of orthopedic surgery. ${ }^{6,8,9,11,19,20}$ Sonication of implants has led to an increased detection rate of bacteria in prosthetic joint infection. ${ }^{22,23}$ The aim of this study was to investigate whether more bacteria could be detected on implants of fracture nonunions by means of the sonication method.

In our study, culture of sonication fluid far outreached all other diagnostic methods, showing positive results in $57 \%$ of atrophic fracture nonunions. To test the sonication method for contamination, ten sterile screws were randomly chosen during different surgical procedures and processed according to the sonication protocol. Bacteria were not detected in any of these samples, making possible contamination during the sonication procedure unlikely. Culture of intraoperative swabs showed poor results, as previously described in the literature, and should therefore only be used if tissue samples or sonication are not available. ${ }^{29}$

Using molecular methods to diagnose implant infections is controversial in the literature, ${ }^{30}$ though a number of conclusive reports exist that advocate the use of such methods. ${ }^{31,32}$ We therefore speculated that molecular diagnostics might significantly enhance the detection rate of bacteria also in atrophic nonunions. Surprisingly, eubacterial 16S rDNA PCR of sonication fluid showed poor results when compared to culture of sonication fluid. This might have been due to a dilution effect in the sonication fluid, which might have produced falsely negative results. When evaluating the five different diagnostic methods, we found that the agreement between all of them was mostly fair or slight only (Table 3), leading us to the conclusion that a discrepancy of diagnostic tests cannot safely rule out an infection.

We also compared the results of group NU with group OM. Interestingly, $40 \%$ of group OM were positive by culture of sonication fluid, even though the implants did not cause any clinical problems and fracture healing was not impaired in these patients. This finding has been previously described by Obst et al. ${ }^{32}$ According to their study, the majority of routinely removed implants were colonized, which raises the question whether bacterial biofilms on implants should be considered pathogenic at all and whether they are actually the cause of nonunions.

There are several possible explanations for this phenomenon. First, even though bacterial biofilms are not considered to be a highly aggressive form of life, ${ }^{33}$ there might be differences in virulence between various bacterial strains and hence in clinical significance. Furthermore, even though the immune system is capable of recognizing and attacking biofilms, ${ }^{34,35}$ there are possible reasons as to why the immune system fails to eliminate biofilm infection in some cases.

First, it could be a matter of time: how fast a biofilm develops (how many bacteria are present) and how fast the immune system responds. Once a biofilm has formed and the immune system fails to cope with the infection, a persistent inflammatory response ensues, which leads to osteoclast generation and tissue degradation. ${ }^{36,37}$

Second, individual differences in the immune response have been described in association with nonunions. According to Szczęsny et al, genetic mutations, such as the TLR4 gene mutation $1 / \mathrm{W}$, have been identified to be associated with ineffective recognition and elimination of bacteria, and thus predispose these patients to impaired fracture healing. ${ }^{38}$ Our data showing improved detection of bacteria on osteosynthetic materials by means of the sonication method are in line with results by others. ${ }^{39}$

The question of whether bacteria detected by culture of sonication fluid are truly pathogenic or whether the 
sonication method should be considered too sensitive for clinical practice is controversial among orthopedic surgeons. It has been suggested that the sonication results be verified by a number - at least 50 colony-forming units per plate and to discard fewer bacteria as insignificant. ${ }^{23}$ However, one should keep in mind that bacteria in biofilms adapt to altered environments (such as culture mediums) very slowly or not at all. ${ }^{40,41}$ There have also been reports of bacteria in a so-called viable but not culturable state, which could easily be misinterpreted as falsely negative if bacterial numbers are the sole criterion for an infection. . $^{42,43}$

Bacteria detected on implants of patients with atrophic nonunions should not be discarded as insignificant, because bacteria were also detected in $40 \%$ of patients without impaired fracture healing. As previously discussed, there are individual reasons why bacteria might add to the pathology of impaired fracture healing in some patients while the majority of fractures heal without complications, despite the presence of bacteria.

We were also interested in evaluating the type of bacteria that can be detected in fracture nonunions. Compared to other diagnostic tools, a wide spectrum of bacteria was found following sonication. Among those were Propionibacterium spp., which for a long time have been considered merely associated with skin-related diseases, but have been linked to implant infections as well. ${ }^{13,14}$ By means of the sonication procedure and by incubation for up to 14 days, we were able to detect propionibacteria that previously have gone unnoticed. In group OM, propionibacteria were even the most frequently detected bacteria $(40 \%)$.

According to Grice et al, ${ }^{44}$ a specific combination of bacteria can be found at sebaceous, moist, and dry-skin areas. We wondered whether a mapping of bacteria detected by implant sonication might offer a clue concerning the origin of bacteria (patient's skin, contamination from surroundings in open fractures, intraoperative contamination), and hence specify antibiotic prophylaxis more precisely. However, due to the large variety of bacteria and the limited number of patients, no significant differences in the distribution of bacteria were able to be detected.

It is widely accepted, that Staphylococcus spp. make up $50 \%-60 \%$ of implant-associated infections, and S. aureus is thought the major causative agent of bone infections. ${ }^{10-12}$ In our study, $55 \%$ of bacteria found in group NU and $30 \%$ found in group OM were in fact Staphylococcus spp.; however, $S$. aureus was not detected in a single case in either group. This highlights once more that new diagnostic methods have enabled us to detect a wider spectrum of bacteria that seem to be associated with implant infections.

\section{Conclusion}

Our data show that bacteria detected on implants by culture of sonication fluid might contribute to the pathology of a large number of atrophic fracture nonunions, and that a previously underestimated variety of bacterial species might be associated with impaired fracture healing.

The pathogenicity of detected bacteria should be discussed in an interdisciplinary setting for each individual case, and further studies on clinical outcome following different treatment strategies might support our finding that culture of sonication fluid is a valuable additional tool to determine a surgical course of action (eg, Masquelet two-step procedure) and to improve antibiotic treatment.

\section{Acknowledgments}

This study was funded by the Center for Orthopedics, Trauma Surgery and Spinal Cord Injury, Heidelberg University Hospital. UD was supported by the OlympiaMorata-Scholarship of the Faculty of Medicine of Heidelberg University.

\section{Author contributions}

All authors contributed toward data analysis, drafting and revising the paper and agree to be accountable for all aspects of the work.

\section{Disclosure}

The authors report no conflicts of interest in this work.

\section{References}

1. Moghaddam A, Zimmermann G, Hammer K, Bruckner T, Grützner PA, von Recum J. Cigarette smoking influences the clinical and occupational outcome of patients with tibial shaft fractures. Injury. 2011; 42(12):1435-1442.

2. Poultsides LA, Liaropoulos LL, Malizos KN. The socioeconomic impact of musculoskeletal infections. J Bone Joint Surg Am. 2010;92(11):e13.

3. Tsukayama DT. Pathophysiology of posttraumatic osteomyelitis. Clin Orthop Relat Res. 1999;(360):22-29.

4. Gaebler C, Berger U, Schandelmaier P, et al. Rates and odds ratios for complications in closed and open tibial fractures treated with unreamed, small diameter tibial nails: a multicenter analysis of 467 cases. J Orthop Trauma. 2001;15(6):415-423.

5. Stengel D, Bauwens K, Sehouli J, Ekkernkamp A, Porzsolt F. Systematic review and meta-analysis of antibiotic therapy for bone and joint infections. Lancet Infect Dis. 2001;1(3):175-188.

6. Schmidmaier G, Lucke M, Wildemann B, Haas NP, Raschke M. Prophylaxis and treatment of implant-related infections by antibiotic-coated implants: a review. Injury. 2006;37 Supp1 2:S105-S112.

7. Moghaddam A, Elleser C, Biglari B, Wentzensen A, Zimmermann G. Clinical application of BMP 7 in long bone non-unions. Arch Orthop Trauma Surg. 2010;130(1):71-76.

8. Gustilo RB, Anderson JT. JSBS classics. Prevention of infection in the treatment of one thousand and twenty-five open fractures of long bones. Retrospective and prospective analyses. J Bone Joint Surg Am. 2002; 84-A(4):682. 
9. Noumi T, Yokoyama K, Ohtsuka H, Nakamura K, Itoman M. Intramedullary nailing for open fractures of the femoral shaft: evaluation of contributing factors on deep infection and nonunion using multivariate analysis. Injury. 2005;36(9):1085-1093.

10. Arciola CR, Campoccia D, Speziale P, Montanaro L, Costerton JW. Biofilm formation in Staphylococcus implant infections. A review of molecular mechanisms and implications for biofilm-resistant materials. Biomaterials. 2012;33(26):5967-5982.

11. Campoccia D, Montanaro L, Arciola CR. The significance of infection related to orthopedic devices and issues of antibiotic resistance. Biomaterials. 2006;27(11):2331-2339.

12. Corvec S, Portillo ME, Pasticci BM, Borens O, Trampuz A. Epidemiology and new developments in the diagnosis of prosthetic joint infection. Int J Artif Organs. 2012;35(10):923-934.

13. Aubin GG, Portillo ME, Trampuz A, Corvec S. Propionibacterium acnes, an emerging pathogen: from acne to implant-infections, from phylotype to resistance. Med Mal Infect. 2014;44(6):241-250.

14. Portillo ME, Corvec S, Borens O, Trampuz A. Propionibacterium acnes: an underestimated pathogen in implant-associated infections. Biomed Research International. 2013;2013:804391.

15. Gristina AG, Jennings RA, Naylor PT, Myrvik QN, Webb LX. Comparative in vitro antibiotic resistance of surface-colonizing coagulasenegative staphylococci. Antimicrob Agents Chemother. 1989;33(6) 813-816.

16. Donlan RM. Role of biofilms in antimicrobial resistance. ASAIO J. 2000;46(6):S47-S52.

17. Fux CA, Costerton JW, Stewart PS, Stoodley P. Survival strategies of infectious biofilms. Trends Microbiol. 2005;13(1):34-40.

18. Campoccia D, Montanaro L, Baldassarri L, An YH, Arciola CR. Antibiotic resistance in Staphylococcus aureus and Staphylococcus epidermidis clinical isolates from implant orthopedic infections. Int $J$ Artif Organs. 2005;28(11):1186-1191.

19. Nelson CL, McLaren AC, McLaren SG, Johnson JW, Smeltzer MS. Is aseptic loosening truly aseptic? Clin Orthop Relat Res. 2005; (437):25-30.

20. Parvizi J, Ghanem E, Menashe S, Barrack RL, Bauer TW. Periprosthetic infection: what are the diagnostic challenges? J Bone Joint Surg Am 2006;88 Suppl 4:138-147.

21. Neut D, van Horn JR, van Kooten TG, van der Mei HC, Busscher HJ Detection of biomaterial-associated infections in orthopaedic joint implants. Clin Orthop Relat Res. 2003;(413):261-268.

22. Tunney MM, Patrick S, Gorman SP, et al. Improved detection of infection in hip replacements. A currently underestimated problem. J Bone Joint Surg Br. 1998;80(4):568-572.

23. Trampuz A, Piper KE, Jacobson MJ, et al. Sonication of removed hip and knee prostheses for diagnosis of infection. $N$ Engl J Med. 2007;357(7):654-663.

24. Dapunt U, Lehner B, Burckhardt I, Zimmermann S, Hänsch GM, Ewerbeck V. Evaluation of implant sonication as a diagnostic tool in implant-associated infections. J Appl Biomater Funct Mater. 2014;12(3):135-140.

25. Suda AJ, Kommerell M, Geiss HK, et al. Prosthetic infection: improvement of diagnostic procedures using $16 \mathrm{~S}$ ribosomal deoxyribonucleic acid polymerase chain reaction. Int Orthop. 2013;37(12):2515-2521.

26. Morawietz L, Classen RA, Schröder JH, et al. Proposal for a histopathological consensus classification of the periprosthetic interface membrane. J Clin Pathol. 2006;59(6):591-597.
27. Landis JR, Koch GG. The measurement of observer agreement for categorical data. Biometrics. 1977;33(1):159-174.

28. Ai-Aql ZS, Alagl AS, Graves DT, Gerstenfeld LC, Einhorn TA. Molecular mechanisms controlling bone formation during fracture healing and distraction osteogenesis. J Dent Res. 2008;87(2):107-118.

29. Aggarwal VK, Higuera C, Deirmengian G, Parvizi J, Austin MS. Swab cultures are not as effective as tissue cultures for diagnosis of periprosthetic joint infection. Clin Orthop Relat Res. 2013;471(10): 3196-3203.

30. Ryu SY, Greenwood-Quaintance KE, Hanssen AD, Mandrekar JN, Patel R. Low sensitivity of periprosthetic tissue PCR for prosthetic knee infection diagnosis. Diagn Microbiol Infect Dis. 2014;79(4):448-453.

31. Portillo ME, Salvadó M, Sorli L, et al. Multiplex PCR of sonication fluid accurately differentiates between prosthetic joint infection and aseptic failure. J Infect. 2012;65(6):541-548.

32. Obst U, Marten SM, Niessner C, Hartwig E. Bacterial DNA from orthopedic implants after routine removal. Int J Artif Organs. 2011; 34(9):856-862.

33. Stewart PS, Costerton JW. Antibiotic resistance of bacteria in biofilms Lancet. 2001;358(9276):135-138.

34. Guenther F, Stroh P, Wagner C, Obst U, Hänsch GM. Phagocytosis of staphylococci biofilms by polymorphonuclear neutrophils: $S$. aureus and $S$. epidermidis differ with regard to their susceptibility towards the host defense. Int J Artif Organs. 2009;32(9):565-573.

35. Günther F, Wabnitz GH, Stroh P, et al. Host defence against Staphylococcus aureus biofilms infection: phagocytosis of biofilms by polymorphonuclear neutrophils (PMN). Mol Immunol. 2009;46(8-9):1805-1813.

36. Dapunt U, Maurer S, Giese T, Gaida MM, Hänsch GM. The macrophage inflammatory proteins MIP1 $\alpha$ (CCL3) and MIP2 $\alpha$ (CXCL2) in implantassociated osteomyelitis: linking inflammation to bone degradation. Mediators Inflamm. 2014;2014:728619.

37. Dapunt U, Giese T, Lasitschka F, Lehner B, Ewerbeck V, Hänsch GM. Osteoclast generation and cytokine profile at prosthetic interfaces: a study on tissue of patients with aseptic loosening or implant-associated infections. Eur J Inflamm. 2014;12(1):147-159.

38. Szczęsny G, Olszewski WL, Zagozda M, et al. Genetic factors responsible for long bone fractures non-union. Arch Orthop Trauma Surg. 2011; 131(2):275-281.

39. Yano MH, Klautau GB, da Silva CB, et al. Improved diagnosis of infection associated with osteosynthesis by use of sonication of fracture fixation implants. J Clin Microbiol. 2014;52(12):4176-4182.

40. Donlan RM, Costerton JW. Biofilms: survival mechanisms of clinically relevant microorganisms. Clin Microbiol Rev. 2002;15(2):167-193.

41. Hall-Stoodley L, Stoodley P. Evolving concepts in biofilm infections. Cell Microbiol. 2009;11(7):1034-1043.

42. Oliver JD. Recent findings on the viable but nonculturable state in pathogenic bacteria. FEMS Microbiol Rev. 2010;34(4):415-425.

43. Kuehl B, Marten SM, Bischoff Y, Brenner-Weiss G, Obst U. MALDIToF mass spectrometry-multivariate data analysis as a tool for classification of reactivation and non-culturable states of bacteria. Anal Bioanal Chem. 2011;401(5):1593-1600.

44. Grice EA, Kong HH, Conlan S, et al. Topographical and temporal diversity of the human skin microbiome. Science. 2009;324(5931): 1190-1192. 


\section{Supplementary material}

Table SI Distribution and number of bacterial species found by culture of sonication fluid: group NU and group OM

\begin{tabular}{ll}
\hline Location & Species and number of isolates \\
\hline Humerus/olecranon $(\mathrm{n}=8)$ & Bacillus spp. (2), Staphylococcus spp. (3), Propionibacterium spp. (2) \\
Ulna/radius $(\mathrm{n}=\mathrm{I3})$ & Propionibacterium sp. (I) \\
Clavicle $(\mathrm{n}=5)$ & Staphylococcus sp. (I), Delftia acidovorans (I), Bacillus sp. (I), Propionibacterium spp. (3) \\
Pelvis $(\mathrm{n}=\mathrm{I})$ & Staphylococcus sp. (I) \\
Femur $(\mathrm{n}=23)$ & Staphylococcus spp. (9), Micrococcus sp. (I), Lactobacillus sp. (I), Oceanobacterium sp. (I), Propionibacterium spp. (I) \\
Fibula/tibia ( $\mathrm{n}=36)$ & Staphylococcus spp. (8), Propionibacterium spp. (2), Enterobacter sp. (I), Corynebacterium sp. (I), Brevibacterium sp. (I), \\
& Bacillus sp. (4), Sporolactobacillus sp. (I), Enterococcus sp. (I) \\
Foot $(\mathrm{n}=8)$ & Bacillus sp. (I), Staphylococcus sp. (I), Micrococcus sp. (I), Propionibacterium sp. (I) \\
\hline
\end{tabular}

Abbreviations: NU, nonunion; OM, osteosynthetic material.

\section{Publish your work in this journal}

Therapeutics and Clinical Risk Management is an international, peerreviewed journal of clinical therapeutics and risk management, focusing on concise rapid reporting of clinical studies in all therapeutic areas, outcomes, safety, and programs for the effective, safe, and sustained use of medicines. This journal is indexed on PubMed Central, CAS,
EMBase, Scopus and the Elsevier Bibliographic databases. The manuscript management system is completely online and includes a very quick and fair peer-review system, which is all easy to use. Visit http://www.dovepress.com/testimonials.php to read real quotes from published authors. 